\title{
The model of students' cognitive activity in the context of interaction with the world
}

\author{
Rimma Kumysheva* \\ Kabardino-Balkarian state university named after H.M. Berbekov, Russia
}

\begin{abstract}
A model of students' cognitive activity in the context of interaction with the world is presented. The model is based on cognitive and humanistic personality theories. The relevance of the model is confirmed by the need to increase personal activity in society in order to manage problem situations in it. The model includes levels of learning tasks, professional activity imitations and solving real problems, which allows consistent professional and personal development of students. The advantages of this model are the continuous students' interaction with the world, which increases their social and practical activity, as well as the value of education in a changing world. The model will be able to form the students' ability to correlate their knowledge and practical experience with problems in reality.
\end{abstract}

The globalization, social transformations, expansion of the information space inherent in modern society have changed not only the way of life and the nature of people's activities. They influenced the personality. At the sight of T.D. Martsinkovskaya, the greatest force impact on the individual was the variability of values and norms, cause-effect relationships in current events [1]. A person in such conditions loses moral and cognitive guidelines, which is accompanied by an increase in anxiety and emotional stress, a weakening of activity and a loss of the meaning of activity.

Meanwhile, the ability to manage situations in the world, redesign them, according to TD Marcinkowskaya [1], increases the degree of predictability of the society development. The people influence on the quality of life in society can reduce the degree of anxiety and emotional tension, as well as increase motivation for activity.

Human activity cannot be carried out in isolation from global changes in the world. Moreover, the activity should be aimed at positive external changes.

The world has undergone a rapid increase in knowledge. Therefore, researchers call it the knowledge society, the intellectual society. The economic, sociological and epistemological shift that has occurred in society under the influence of information technology puts pressure on the institution of education around the world and encourages it to intensely respond to the new needs of various activity fields and increase the readiness of graduates to work in new living conditions [2, p. 425].

The unsuitability of traditional teaching methods for vocational education is revealed. Work in modern society requires graduates to transform the information received while

\footnotetext{
* Corresponding author: rkumysh@mail.ru
} 
education into new ideas and their immediate practical implementation; modern students will have to solve real production and social problems in the future [3, p. 60-61].

Education specialists are increasingly proposing models and conceptions of training aimed at enhancing the role of its practical component and solving problem tasks. For example, the so-called "smart education" should realize a discursive understanding of cognitive society models in order to activate the personality socio-cultural growth, which will ensure the perfection of professional skills in the future [4, p. 159].

Researchers also suggest: 1) to teach students to build their own knowledge, to design new models of activity [5]; analyze problem situations and create conditions for the exchange of solutions to each other [6];2) to use computer modeling of real observable life problems [7] and Virtual Reality (VR) to model solutions to problem situations [8] and others.

All proposed measures contain common points: the interaction of students with the real world and the creation of their own new ideas while education. This is the requirement of modern society - to prepare students for activities in a changing world and solve problems that may arise in the future.

Such a requirement for education is natural. According to cognitive psychology, knowledge is an internal representation of the external world, and the human body is an information processor that transforms the external world into symbols [9, p. 87]. A person is capable to transform the world into symbols to the same extent that he can transform the world through knowledge. According to humanitarian psychology, knowledge involves the transformation of personality, it gives him, in particular, the ability to transform the world [9, p. 117-118].

Cognition was initially carried out in the process of human interaction with the world. Methods of observation, comparison, measurement, and others arose while direct interaction with the world. When mankind has accumulated sufficient experience in studying the world and the need for its dissemination has been outlined, the first teaching methods have arisen that are still in use now. Theorization of knowledge and formalization of training, which gradually replaced the natural cognitive process, turned the learning process into an accumulation of information, often without awareness of its meanings and functions for further activities. Modern higher education can't be formalized and contain only the accumulation of information in students' memory. Modern graduates of higher education should be prepared for practical activities and for making decisions in the changing conditions of activity. Society needs useful specialists who are ready to solve relevant production and fundamental problems.

True knowledge is always knowledge of the world and how to interact with it. Therefore, modern education should be carried out in the interaction of students with the world.

The world for a person is defined as: 1) the totality of objects used by a person and on which human activities are directed; 2) situations that involve human participation and which unite people; 3 ) the rules of joint activity and communication between people. The world is represented as: 1) a set of objects, 2) the social environment, 3) the information space [10, p. 94]. Everything that a person interacts with can be represented as objects, situations, or combinations of objects that require human participation. The world contains three levels: subject, social and information. People interact with all levels of the world. Therefore, the cognitive activity of students should represent this interaction with the world at all three levels.

Man interacts with the world through activity. Consequently, the quality of life depends on the quality of activity and implementation its results. Therefore, it's so important that graduates of higher education are able to correlate the real life problems with what professional activities can offer to solve them, to possess professional skills as so as they 
can choose and creatively apply professional possibilities in reality. This should be taken into account while designing the cognitive activity of students.

The students' cognitive activity model, which we propose, aims to increase the degree of personality's orientation in the world and its problems, as well as ensure the readiness of graduates to recognize and solve the problems of the world.

We proceed from the fact that professional activities are carried out in the contexts of three levels of the world: informational, social and substantive. We call them: information world, social world, objective world. In the context of three worlds, a person consistently performs types of cognitive activity: observation, problem identification, problem statement, search for ways to solve it, problem solving, entering the result directly into the context of the world.

Cognition starts with a lack of knowledge for orientation in a problem situation. This means that the first step in cognition is the recognition of the need for information and the statement of the task corresponding to the situation. A man is looking for a means of orientation in the information world. The found information is used by a person in a situation and, if necessary, is changed until a result is achieved. The result of task solving is discussed by the subject with colleagues and modified. This process is carried out in the social world. The final result of cognitive activity is embedding in the appropriate level of the world.

The model of students' cognitive activity in the context of interaction with the world is based on this activity scheme. But, since the model is a component of the educational process, it provides for situational levels: the learning task, imitation of professional activity and social interaction, real problems learned from direct interaction with the world.

At the level of the educational task, students interact with the information world. The search for information and its reconciliation with the task, its solution and verification of the result are carried out internally. The cognitive result of actions at this level is the development of an algorithm for solving problems and the ability to evaluate own actions.

The obtained cognitive result becomes the basis for actions at the level of professional activity imitation. Students apply an algorithm for solving problems to situations that represent episodes of professional activity. Activities are carried out on an external plane. The cognitive result at this level is the experience of practical activities and social interaction.

The gained experience allows students to move to the level of real problem situations requiring professional intervention. At this level, students use previously developed action algorithms and skills on the internal and external activity plans. Learning activities are carried out in the real world. Students get the opportunity to directly influence the problems of the world (Figure 1). 


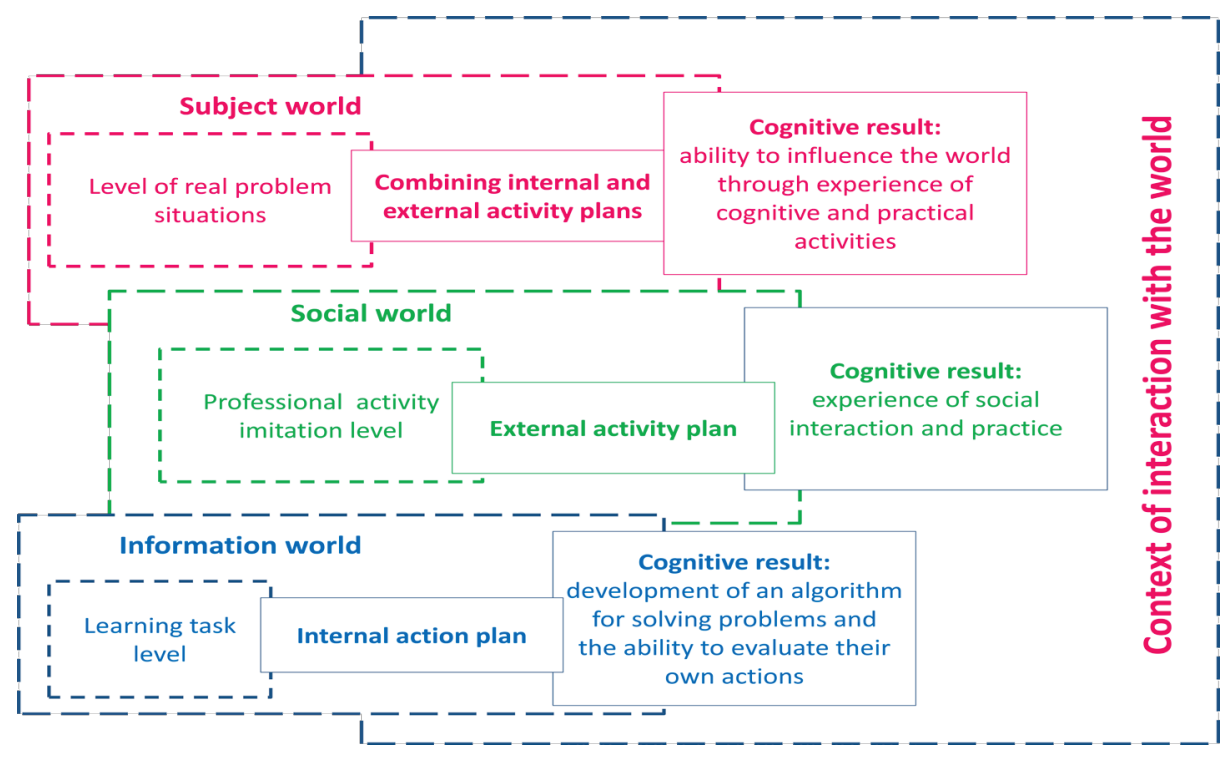

Fig. 1. The model of students' cognitive activity in the context of interaction with the world

The proposed model of students' cognitive activity in the context of interaction with the world will help students to develop their cognitive sphere, realize the value of education and build confidence in the controllability of problem situations in the world. In professional terms, the main achievement will be the readiness of graduates to solve new problems in the world.

\section{References}

1. T.D. Marcinkovskaya, Sovremennaya social'naya psihologiya: teoreticheskie podhody i prikladnye issledovaniya, 12, 5-17 (2013)

2. J. Pei-Ling Tan Asia Pacific, Education Review, 37, 425-436 (2017)

3. Eman Gheith \& Nahil M. Aljaber International Education Studies, 10-6, 60-71 (2017)

4. V.Voronkova, O.Kyvliuk, Future human image, 5,154-162 (2017)

5. I.Vali Procedia $\square$ Social and Behavioral Sciences, 76, 388-392 (2013)

6. M. Alles, T. Seidel, A., Grischne International Education Studies, 11- 1, 11-24 (2018)

7. Wael A. Salah, Abu Sneineh Anees, Modern Applied Science, 11- 8 (2017)

8. Yonit Nissim, Eyal Weissblueth, International Education Studies, 10- 8, 52-59 (2017)

9. N.Smit, Sovremennye sistemy psihologii (EUROZNAK, St. Petersburg, 2003)

10. R.M. Kumysheva, Sbornik XX simpoziuma, 93-96 (2015) 